\title{
Daylight ratio, luminance, and visual comfort assessments in typical Malaysian hostels
}

\begin{abstract}
Conventional tropical building designs are experiencing a new paradigm in their environmental response to improve lighting ambiance and occupantsôvisual comfort through the exploitation of daylighting. However, it is important for architects to understand that flaws in daylighting strategies could lead to disadvantages as they could hinder vision, cause discomfort, increase interior heat gain, and result in excessive energy demands. The objective of this study was to assess how occupantsôperceived their visual conditions through daylight ratio and luminance level measurements. Measurements were conducted throughout a 2month period starting from 12th May to 3rd July 2007. Three case studies were conducted at typical Malaysian hostels located in the Klang Valley. Those selected were: the Twelfth Residential College, Universiti Malaya (H1); the Eleventh Residential College, Universiti Putra Malaysia (H2); and Murni Student Apartments, Universiti Tenaga Nasional (H3). The daylighting source in all these case studies were from side-lit windows. Overall, the findings suggested that occupants were at ease with the level of daylighting available in their rooms even though rooms that were shaded by projecting balconies (i.e.,: H1) were dimmer than the rooms that were not shaded (i.e.,: $\mathrm{H} 2$ and $\mathrm{H} 3$ ).
\end{abstract}

Keyword: Daylight ratio; Illumination; Luminance; Objective measurement; Side-lit window; Subjective measurement; Visual comfort 